\title{
Utilization of extracorporeal membrane oxygenation support for high-risk percutaneous coronary interventions: experience from the Clinical Hospital Dubrava
}

\section{Mario Sičaja*, \\ Boris Starčević}

Clinical Hospital Dubrava, Zagreb, Croatia
RECEIVED:

August 31, 2015

ACCEPTED:

September 17, 2015
KEYWORDS: extracorporeal membrane oxygenation, percutaneous coronary interventions, complex inteventions.

CITATION: Cardiol Croat. 2015;10(9-10):237. | DOI: http://dx.doi.org/10.15836/ccar.2015.237

*ADDRESS FOR CORRESPONDENCE: Mario Sičaja, Klinička bolnica Dubrava, Av. Gojka Šuška 6, HR-10000 Zagreb, Croatia. / Phone: +385-91-4060989 / E-mail: mario.sicaja@gmail.com

ORCID: Mario Sičaja, http://orcid.org/0000-0003-0773-4720 • Boris Starčević, http://orcid.org/0000-0002-3090-2772

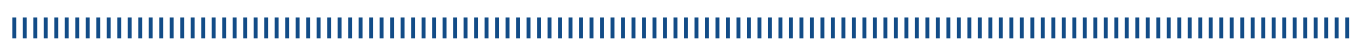

Extracorporeal membrane oxygenation (ECMO) is a recognised rescue treatment option frequently utilized in the pediatric population or the treatment of severe cardiorespiratory failure. Recent advances in the field have introduced ECMO usage well beyond cardiac surgery operating theatre. There is an increasing evidence of usage in adults, particularly in the setting of interventional cardiology. ECMO exists in two variations: a venovenous (VV-ECMO) variation for respiratory and an arteriovenous form (VA-ECMO) for total cardiopulmonary support. The main advantages of VA-ECMO support are superb hemodynamic support of the body perfusion in patients with severe heart failure, rapid, rapid initiation in the emergency setting, possibility of patient transport and serving as a bridge to the definite treatment modality in critically ill patients. Main drawbacks are high device related morbidity, need for continuous anticoagulation and the need for adequate training of ECMO team members., ${ }^{1,2}$

We present our initial experience with VA-ECMO use in the setting of high-risk percutaneous coronary interventions. 